\title{
Estimation of uncertainty of laser interferometer measurement in industrial robot accuracy tests
}

\author{
Jerzy Józwik ${ }^{1, *}$, Elżbieta Jacniacka ${ }^{1}$ and Dawid Ostrowski ${ }^{2}$ \\ ${ }^{1}$ Lublin University of Technology, Mechanical Engineering Faculty, Department of Production Engineering, 36 Nadbystrzycka Street, \\ 20-618 Lublin, Poland \\ ${ }^{2}$ The State School of Higher Education, The Institute of Technical Sciences and Aviation, 54 Pocztowa Street, 22-100 Chełm, Poland
}

\begin{abstract}
The subject of this article is the assessment of measurement uncertainty of the Renishaw XL80 laser interferometer in MOTOMAN HP20 industrial robot inaccuracy test. The paper presents the methodology for estimating the measurement uncertainty of the system used in tests. Estimates of standard and extended uncertainty were calculated for the given research method. These uncertainties are based on the information included in the device calibration certificate (method B) but also on the basis of measurements and statistics (method A). The authors proposed their own research methodology, taking into account measurement capabilities of the applied system and the specific character of the robot work. Calculations employed universal computing systems based on standard algorithms. The results obtained from the research and calculations precisely defined key uncertainties allowing for objective evaluation of industrial robot errors identified by the Renishaw XL80 system.
\end{abstract}

\section{Introduction}

Uncertainty of laser interferometer measurement includes a series of uncertainties that take into account the impact of major errors affecting the measurement result. Uncertainty is defined as a certain "doubt" about the value of the measurement result. It is presented as an interval around the measurement result, within which, with a certain probability, lies the true value of the measured value [1-2]. Estimation of measurement uncertainty of an industrial robot presents a number of different difficulties, which are discussed in the paper [3]. Literature [4-9] indicates that although laser interferometry constitutes an effective method of measuring deviation of positioning accuracy the measurement result should be presented as a range, taking into account the uncertainty of its acquisition. In work $[10,11]$ ABB IRB 1600 robot positioning repeatability was determined using a laser interferometer. Measurements were carried out along three orthogonal linear tracks of $1000 \mathrm{~mm}$ (horizontal tracks) and $800 \mathrm{~mm}$ (vertical tracks). Each of the tracks had 5 measuring positions (standby time was $5 \mathrm{~s}$ ), specified in 30 repetitions. Positioning repeatability in horizontal axes was in the range of $6 \mu \mathrm{m}$ to $14 \mu \mathrm{m}$ while in the vertical axis $25 \mu \mathrm{m}$. Positioning deviation values do not exceed $650 \mu \mathrm{m}$. The authors of [10-11] as well as others [12-23], however, do not express the uncertainty of the obtained results. Similarly, in the work [13] n industrial robots errors (Cloos Romat 310, The ABB IRB 6400S and KUKA KR125) determined with analogous methods, do not have a specific measurement uncertainty. The largest recorded deviation of positioning accuracy was in the range of $-1600 \mu \mathrm{m}$ to $+300 \mu \mathrm{m}$. However, these results may not be considered useful because of the lack of estimation of measurement uncertainty. According to the cited residual results $[4,5$, 10-23], the inaccuracy of the robot is determined by a number of factors (geometric, dynamic, kinematic, thermal, systemic, structural) and each of them introduces a specific uncertainty to the measurement result. This assessment requires an accurately assessed measurement uncertainty [1-13]. Only proper estimation of uncertainty will allow for objective estimation of robot inaccuracies and selection of optimum measurement method $[1,2,4]$. Today the theory of measurement uncertainty has replaced the theory of measurement accuracy (measurement error). Uncertainty theory is commonly recognized, universal and accepted by all metrology organizations. So it is important to assume that the accuracy of any measurement is described by its uncertainty $[1,2]$.

\section{Research methodology}

\subsection{Research set-up}

In experimental work it is necessary to estimate statistical components of laser interferometer measurement uncertainty, the following positions and computerized measurement and calculation systems were used:

\footnotetext{
* Corresponding author: j.jozwik@pollub.pl
} 
- MOTOMAN HP20 industrial robot, as a research object,

- Renishaw XL80 interferometer laser system with $\mathrm{XC}-80$ compensator and temperature, pressure and humidity sensors,

- Excel computing environment,

- Statistica computing environment,

- Specialized software for data recording and analysis LaserXL,

- XCal-View 2.2 software.

\subsubsection{Object of research}

The object of accuracy and repeatability testing of positioning was a universal, six-axis industrial robot MOTOMAN HP20 from Yaskawa (Fig. 1a). Maximum lifting capacity of the robot is $20 \mathrm{~kg}$. The robot is controlled by a YASNAC FS 100 controller. Fig. 1b shows the positioning of the robot on research station. a)

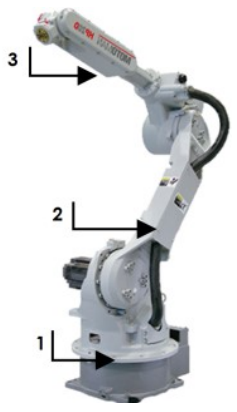

b)

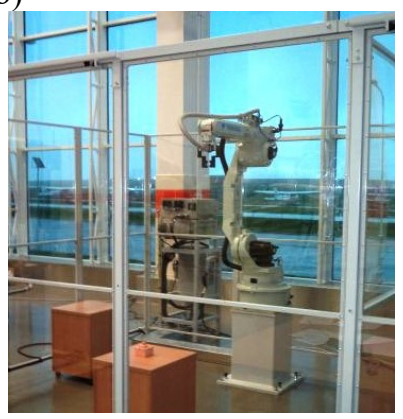

Fig. 1. Industrial robot HP20, a) general view, b) robot's positioning on research station, 1, 2, 3-robot connectors.

All MOTOMAN HP20 work axes are rotary axes. The range of movement of individual axes of the robot are: $\mathrm{S}$ axis $\left( \pm 180^{\circ}\right), \mathrm{L}$ axis $\left(+155^{\circ} /-110^{\circ}\right), \mathrm{U}$ axis $(+255$ $\%$-165 $\left.{ }^{\circ}\right), \mathrm{R}$ axis $\left.\left( \pm 200^{\circ}\right)+230^{\circ} /-50^{\circ}\right)$ and $\mathrm{T}$ axis $\left( \pm 360^{\circ}\right)$. The axis of rotation of joint 1 is vertical, while the axes of joints 2 and 3 are horizontal axes. The maximum distance in the axis perpendicular to the base plane is $3063 \mathrm{~mm}$, and in the axis parallel to the base plane $1717 \mathrm{~mm}$. Repeatability of positioning based on robot calibration certificate and the manufacturer's assessment is $0.06 \mathrm{~mm}$.

\subsubsection{Measurement set-up}

Motoman HP20 industrial robot precision tests were performed with non-contact laser interferometry. The accuracy and repeatability of positioning was tested with the Renishaw XL80 system, composed of: a laser generating a stable radiation beam (Fig. 2a), an XC-80 compensator with temperature, pressure and humidity sensors (Fig. 2b), a set of optical measurement systems (Fig. 2c), a stand with a mounting table and specialized software for data logging and analysis LaserXL. The XL80 system enables measurement of linear and angular (rotational) deviations, flatness, straightness and perpendicular deviation. The accuracy of linear measurement declared by manufacturer is $\pm 0.5 \mathrm{ppm}$ and,

thanks to the use of a compensator, is maintained throughout the range of changes in environmental conditions (temperature, pressure, humidity).

a)

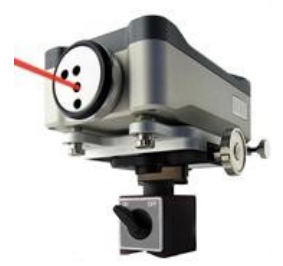

c)

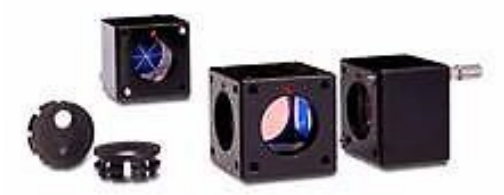

Fig. 2. Basic elements of the XL80 laser interferometer system, a) laser, b) XC-80 compensator with temperature, pressure and humidity sensors, c) optical measurement systems.

The tested robot was mounted on a stand guarded by special safety barriers, whose task is to ensure safety and stable working conditions of the robot and of the performed measurements.

\subsection{Test settings}

In the paper, the authors proposed their own research methodology, taking into account the measurement capabilities of the applied system and the specificity of the robot's work. This methodology is optimized for the duration of the test and the possibility of estimating the inaccuracy of the robot in industrial conditions. The diagram of the measurement method is shown in Fig. 3. The Cartesian coordinate system $X^{\prime}, Y^{\prime}, Z^{\prime}$ has been adopted for technical measurement of deviation accuracy with a laser interferometer. Measurement consisted of alternating (3 runs), bidirectional linear test. The target velocity of motion was vf $=50 \mathrm{~mm} / \mathrm{s}$. In each of the three selected planes (along the $X^{\prime}, Y^{\prime}$ and $Z^{\prime}$ axis), five parallel measuring paths (S1-S5) were defined at a distance of $250 \mathrm{~mm}$ (Fig. 3).

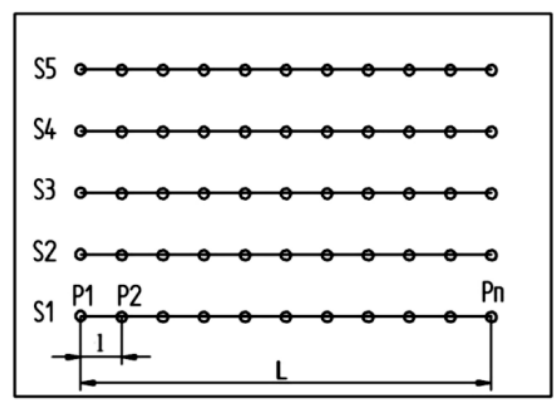

Fig. 3. Layout of paths and points of measurement of deviation of positioning accuracy, using a laser interferometer

On each path, measuring points (P1-Pn) spaced at $1=$ $100 \mathrm{~mm}$ apart were specified. The lengths of the paths 
(L) and the number of measurement points (np) were equal to:

$$
\begin{array}{ll}
\text { along } X^{\prime} \text { axis: } & \mathrm{LX}^{\prime}=1100 \mathrm{~mm}, \mathrm{np}=12 \\
\text { along Y' axis: } & \mathrm{LY}^{\prime}=1500 \mathrm{~mm}, \mathrm{np}=16 \\
\text { along } \mathrm{Z}^{\prime} \text { axis: } & \mathrm{LZ}=900 \mathrm{~mm}, \mathrm{np}=10
\end{array}
$$

The orientation of the accepted Cartesian coordinate system was presented in Fig. 4.

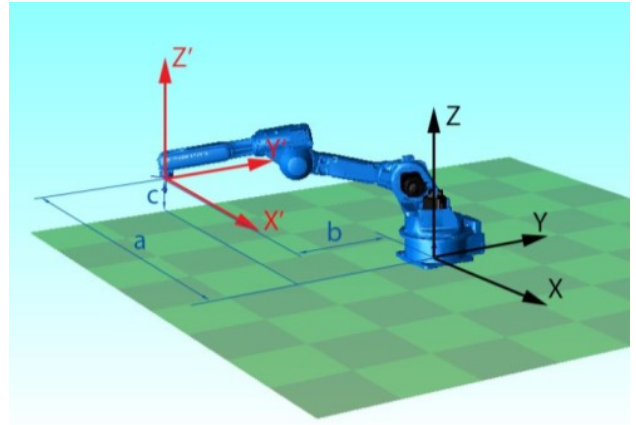

Fig. 4. Definition of the location of the beginning of the measurement coordinate system $\left(X^{\prime}, Y^{\prime}, Z^{\prime}\right)$ in the base coordinate system of the robot $(\mathrm{X}, \mathrm{Y}, \mathrm{Z})$ for linear measurements along the $\mathrm{X}$ and $\mathrm{Y}$ axes, where: $\mathrm{a}, \mathrm{b}, \mathrm{c}-$ displacement values in individual axes $\mathrm{X}, \mathrm{Y}, \mathrm{Z}$.

Such assumption makes it much easier to analyze the measured results. The definition of the starting position of the coordinate system $\left(X^{\prime}, Y^{\prime}, Z^{\prime}\right)$ in the robot's base coordinate system $(\mathrm{X}, \mathrm{Y}, \mathrm{Z})$ was dictated by the spatial accessibility of elements of the measuring system and the studied work space availability . The displacement in the Cartesian coordinate system were respectively $\mathrm{a}=$ $550 \mathrm{~mm}$ in the $\mathrm{X}$ axis, $\mathrm{b}=1500 \mathrm{~mm}$ in the $\mathrm{Y}$ axis and $\mathrm{c}=450 \mathrm{~mm}$ in the $\mathrm{Z}$ axis. The beginning of the coordinate system was defined in analogically to the $Z$ axis. The Cartesian system displacement was $b^{\prime}=1500$ $\mathrm{mm}$ in the $\mathrm{Y}$ axis and $\mathrm{c}^{\prime}=200 \mathrm{~mm}$ in the $\mathrm{Z}$ axis. The arrangement of individual measuring paths along the selected axes $\mathrm{X}, \mathrm{Y}$ and $\mathrm{Z}$ is shown in Fig. 5.

Measurement conditions, i.e. temperature, humidity and pressure were monitored by a laser interferometer meteorometer. Motoman HP20 was programmed offline. Before the first and after the last measuring point, a trip was programmed to compensate for the recurrence error. The test was carried out without load and with a load of $8.6 \mathrm{~kg}$. The load selection was dictated by the most commonly used displacement mass by the robot effector. The measurements were made using a linear measurement algorithm, according to the ISO standard. XCal-View 2.2 software was used to record measurement data, including graph generation and extensive statistical analysis of results based on the applicable ISO standard.
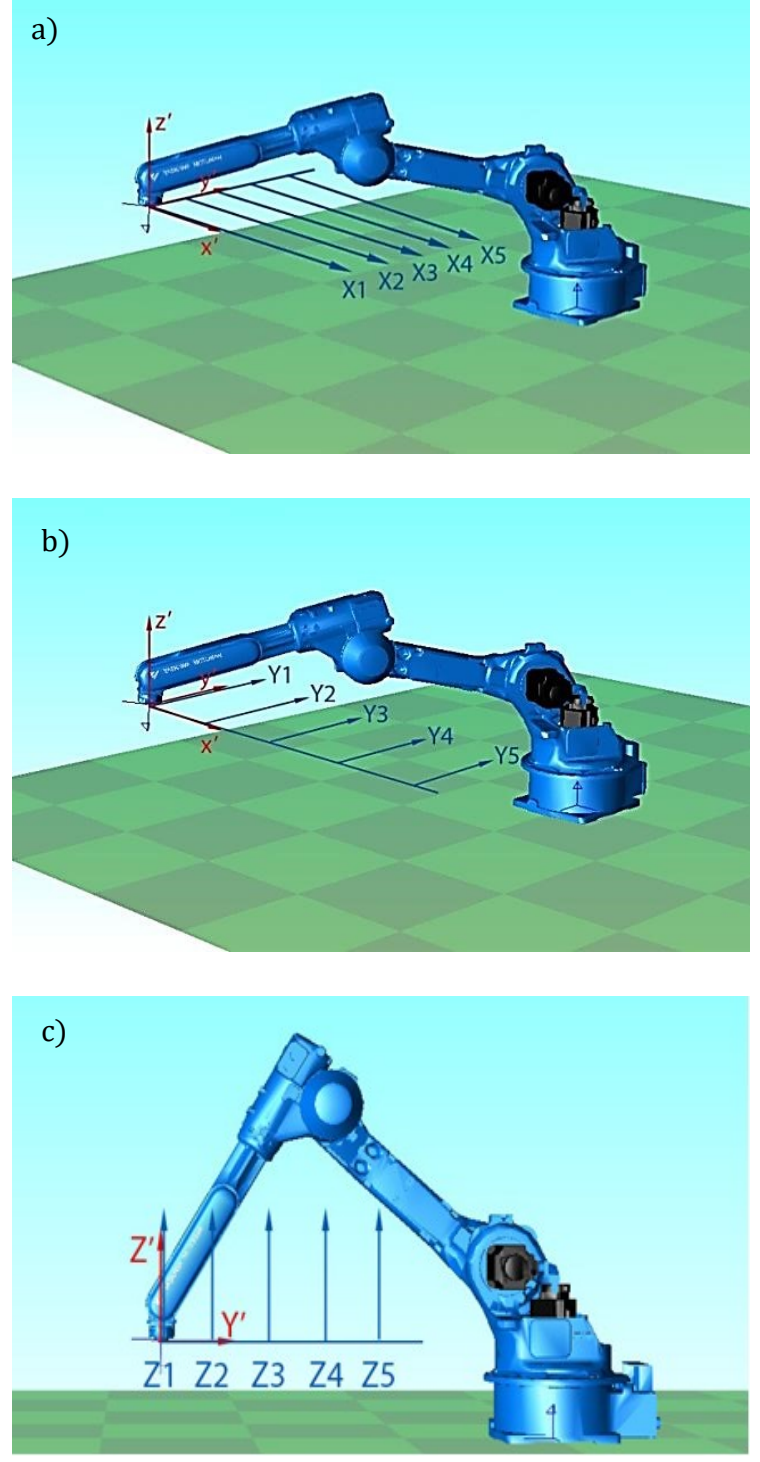

Fig. 5. Location of measurement paths in space while measuring a) along $\mathrm{X}$ axis, $\mathrm{b}$ ) along $\mathrm{Y}$ axis, $\mathrm{c}$ ) along $\mathrm{Z}$ axis.

\section{Test results}

The conducted experimental research allowed us to collect the data necessary for determining statistical uncertainty components. These results were used for the estimation with the A method. The example of experimental data in the direction of the $\mathrm{Y}$ axis is presented in Fig. 6.

Based on the conducted measurements, using specialized software $\mathrm{XCal}-\mathrm{View} 2.2$ we were able to determine the values of accuracy and repeatability of the positioning of the robot, such as: unidirectional positioning accuracy $\mathrm{A} \uparrow, \mathrm{A} \downarrow$, bidirectional positioning accuracy $\mathrm{A}$, unidirectional positioning repeatability $\mathrm{R} \uparrow$, $\mathrm{R} \downarrow$, bidirectional $\mathrm{R}$ positioning repeatability, axial $\mathrm{B}$ feedback. For these values, a complex standard uncertainty and extended uncertainty were defined. 


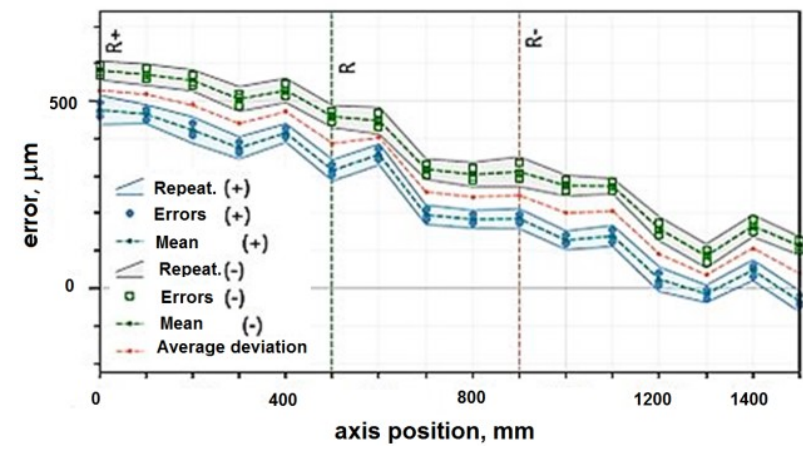

Fig. 6. Positional displacements along the selected measurement path Y1, in case of test without load.

\section{Estimation of uncertainty}

Uncertainty in laser interferometer measurement includes a series of uncertainties that take into account the impact of major errors affecting the measurement result (uncertainty budget). The analysis includes the following budget components: cosine error, Abbe error, dead path error, thermal error, maximum interferometer error, temperature sensor limit error, and thermal expansion factor error. Uncertainty resulting from the above errors was taken into account when estimating the uncertainty of measurement accuracy and repeatability of positioning. The information included in the calibration certificate of the device was used, along with the measurement results and statistical data of the results obtained in the measurements. Individual statistical components of measurement uncertainty were estimated with method $\mathrm{A}$ and non-parametric components were estimated with method B. Expanded uncertainty $U$ was determined on the basis of equation (1)

$$
U= \pm u_{c} k
$$

where: $u_{c}-$ the adopted standard uncertainty, $\mathrm{k}-$ expansion factor.

Complex standard uncertainty $u_{c}$, determined from the equation (2)

$$
u_{c}= \pm \sqrt{u_{A}^{2}+\sum_{i=1}^{n} u_{B i}^{2}}
$$

where: $u_{A}-$ standard uncertainty estimated with method A (statistical), $u_{B i}-$ standard uncertainties beyond the statistical method $\mathrm{B}$.

Complex standard uncertainty includes both the uncertainty component $u_{A}$ as well as all non-statistical components $u_{B i}$ estimated with $\mathrm{B}$ method. Standard uncertainty $u_{A}$ estimated with method A (statistical) was determined on the basis of dependency (3)

$$
u_{A}= \pm \sqrt{\frac{\sum\left(x_{i}-\bar{x}\right)^{2}}{n(n-1)}}
$$

Where: $x_{i}-$ single measurement result, $\bar{x}-$ measurement results average, $\mathrm{n}-$ number of measurements and the sum of squares of component non-statistical uncertainties determined with method B on the basis of the formula (4)

$$
\sum_{i=1}^{n} u_{B i}^{2}=u_{B c o s}^{2}+u_{B A b b}^{2}+u_{B d r m}^{2}+u_{B p r z}^{2}+u_{B T}^{2}+u_{B \alpha}^{2}
$$

where: $u_{B i}^{2}$ - component uncertainties resulting from device errors and measurement conditions, estimated by the method $\mathrm{B}, u_{B \cos }^{2}$ - component taking into account the cosine error, $u_{B A b b}^{2}$ - component taking into account the Abbe error, $u_{B d r m}^{2}$ - component taking into account the dead path error, $u_{B p r z}^{2}-$ component taking into account the influence of maximum limit error of interferometer, $u_{B T}^{2}$ - component taking into account the influence of the limit error of the sensor during temperature measurement, $u_{B \alpha}^{2}$ - component taking into account the error of estimation of thermal expansion coefficient.

Considering the specific character of measurements and setting of individual components of the interferometer during measurements, the cosine error values and the Abbe error were assumed to be insignificant and of negligible effect on the measurement result. Additionally, it was pointed out that the phenomena that are the source of these errors are controlled by the system software, and the measurement itself is only possible if all sources of their origin are removed. Another reason for not taking this error into account is that its value is so small that, relative to the expected measurement accuracy, the resulting uncertainty can be treated as a small second order.

\subsection{Cosine error}

A cosine error occurs when the laser beam is not parallel to the axis of motion of the robot arm (Fig. 7).

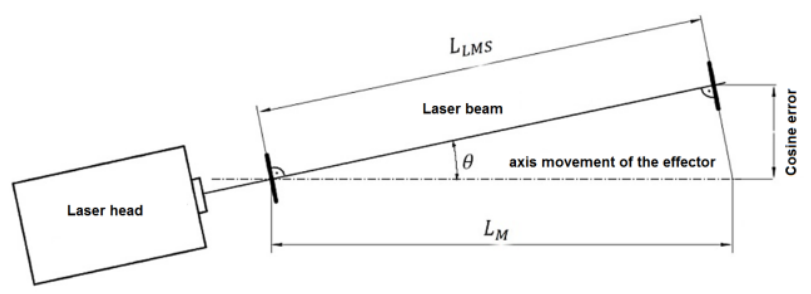

Fig. 7. Schematic representation of origin of cosine error resulting from the lack of parallelism of the laser beam to the axis of motion of the examined object.

Therefore, measurement distance $\mathrm{L}_{\mathrm{LMS}}$ on the path from point $\mathrm{A}$ to point $\mathrm{B}$, will be smaller than the actual path travelled by the $\mathrm{L}_{\mathrm{M}}$ robot arm, according to the relationship (5).

$$
L_{L M S}=L_{M} \cdot \cos \theta
$$

Minimizing this error should be done by aligning the laser beam with respect to the direction of travel of the robot shift assembly. It was therefore assumed that the uncertainty taking into account the lack of parallelism of the laser path to the axis of motion of the examined object is close to zero $u_{-}$Bcos $\approx 0$. The basis for this assumption is the condition stating that the realization of the measurement in question is possible only when the error is small enough to allow the measurement to be fully carried out. In the analyzed case, the condition was fulfilled during the measurements. Adjustments of the 
interferometer used were controlled from the measurement system software, and the cosine error was small enough that the uncertainty of the source could be omitted.

\subsection{Abbe error}

Due to the fact that estimating the Abbe error is very difficult, it is assumed that the robot is included as part of the positioning deviation and is not considered as a source of measurement uncertainty. The Abbe error results from the angular movement of the robot arm with the reflector in a given direction when the measurement is made at a distance offset by a certain displacement (i.e. the distance called the Abbe offset) from the actual displacement point. Thus, the actual distance is different from the measured distance (Fig. 8).

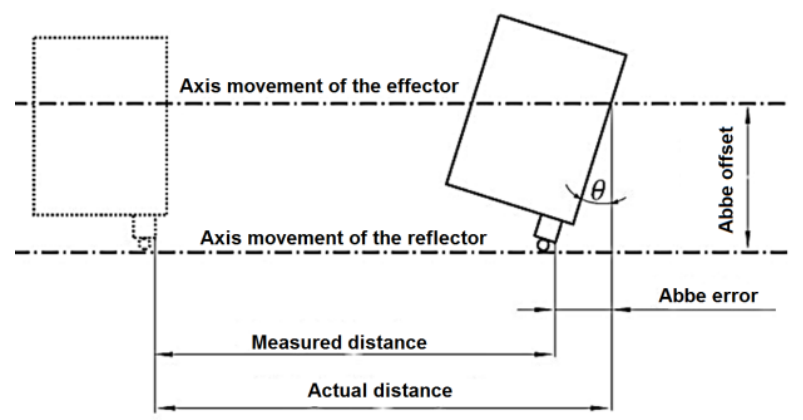

Fig. 8. Geometric interpretation of the Abbe error occurrence.

In the test case Abbe's offset was zero, because the headlight was the same as the robot's frame. It can therefore be assumed that the value of uncertainty also tends to zero, and therefore $u_{B A b b} \approx 0$.

\subsection{Dead path error}

Another factor affecting the result of the interferometric measurement is the dead path error (Fig. 9). Dead path error occurs when there is no compensation of the length of the laser beam path. Changing the length of a laser path occurs when ambient conditions affecting the wavelength of the measurement are drastically changing, for example the temperature of the material on which both the interferometer and the reflector are mounted changes, changing inter alia their distance.

Due to the negligible changes in temperature during measurements in a relatively long time, not exceeding $1.23{ }^{\circ} \mathrm{C}$ and the type of substrate on which these elements were placed and no change of dimensions (stable concrete slab), these factors were considered irrelevant from the point of view of the conducted measurement.
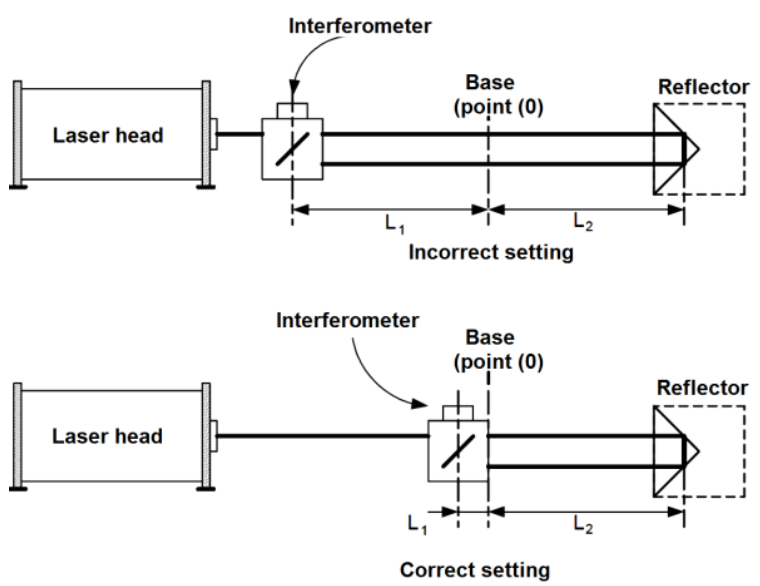

Fig. 9. Setting of the system optics, minimizing the dead path error value.

Literature analysis also shows [1, 2, 4] that the dead path error after normalization and proper placement of stationary and movable optics relative to a representative zero point (the so-called base) is negligible and there is no need to include it in budgeting of measurement uncertainty. This error is smaller, the closer the interferometer is to the "base" (Fig. 9). Correct alignment of the system optics, minimizing the value of the dead path error is shown in Fig. 9. Therefore, the standard uncertainty taking into account the dead path error is close to zero $u_{B d r m} \approx 0$.

\subsection{Uncertainty taking into account the influence of the maximum limit error of the interferometer}

The uncertainty analysis included the effect of the maximum interferometer error, defined as MPE. The value of $M P E$ error was derived from the qualification certificate of the device. $M P E$ does not include corrections related to standardization of measurement results to the temperature of $20{ }^{\circ} \mathrm{C}$. The resulting uncertainty of the instrument (laser) $u_{B p r z}$ with adoption of normal probability distribution is based on the following relationship (6)

$$
u_{B p r z}= \pm \frac{M P E}{2} x_{i j}
$$

where: MPE - the maximum limit error estimated by the manufacturer with a known expansion factor $\mathrm{k}$ (in our case $\mathrm{k}=2$ ) when measured using environmental compensation stations - temperature, humidity, pressure (MPE $= \pm 0.5 \mathrm{ppm}$ in the first year of use, MPE $= \pm 1 \mathrm{ppm}$ - in the next three years of use) and $x_{i j}$ - current preset position.

\subsection{Uncertainty taking into account the influence of the temperature sensor limit error}

With respect to the conducted robot tests, the impact of the sensor error on temperature was taken into account in estimating uncertainty. The general form of uncertainty of standard temperature measurement $u_{B T}$ with many sensors used during the experiment and the adoption of 
a rectangular probability distribution can be determined from the formula (7):

$$
u_{B T}= \pm \frac{\sum_{i=1}^{n} M P E_{T_{i}}}{n \sqrt{3}}
$$

where: $M P E_{T_{i}}$ - maximum limit error of the temperature sensor (according to calibration data provided by the manufacturer $M P E_{T_{i}}= \pm 0.1^{\circ} \mathrm{C}, n-$ number of temperature sensors during the test).

For the case under consideration, the change in temperature values during the measurements did not exceed $\Delta \mathrm{T}=1.23^{\circ} \mathrm{C}$, and the uncertainty of standard temperature measurement $u_{B T}$, assuming rectangular probability distribution, was determined from (8):

$$
u_{B T}= \pm \frac{M P E_{T}}{\sqrt{3}}
$$

Limit error value $M P E_{T}$ was adopted according to the calibration certificate on the level of $\pm 0.1^{\circ} \mathrm{C}$.

\subsection{Uncertainty of determination of thermal expansion coefficient}

Taking into account the possibility of extension of the standard, the standard uncertainty of the coefficient of thermal expansion was also determined $u_{B \alpha}$. The standard uncertainty of determining the coefficient of thermal expansion with rectangular probability distribution is described by the equation (9):

$$
u_{B \alpha}= \pm \frac{\Delta \alpha}{\sqrt{3}}
$$

where: $\Delta \alpha$ - limit deviation of the coefficient of thermal expansion.

On the basis of literature $[1,2,4]$ it was assumed that the limit deviation of the coefficient of thermal expansion amounts to $\Delta \alpha=1.5 \cdot 10^{-6} \frac{1}{{ }^{\circ} \mathrm{C}}$, and the value $\alpha=11.6 \cdot 10^{-6} \frac{1}{{ }_{0}}$. Taking the above into account, the standard uncertainty of determining the coefficient of thermal expansion $u_{\alpha}$ was defined (10):

$$
u_{B \alpha}= \pm\left(\frac{1.5}{\sqrt{3}} \cdot 10^{-6}\right) \frac{1}{{ }^{\circ} \mathrm{C}}
$$

Therefore finally, the sum of the uncertainty squares estimated with method B is (11):

$$
\sum_{i=1}^{n} u_{B i}^{2}=u_{B p r z}^{2}+\left(\frac{\partial x_{i j}}{\partial(\Delta T)} \cdot u_{T}\right)^{2}+\left(\frac{\partial x_{i j}}{\partial(\alpha)} \cdot u_{\alpha}\right)^{2}(11)
$$

and complex standard uncertainty $u_{c}$, may be determined from the equation (12):

$u_{c}= \pm \sqrt{u_{A}^{2}+u_{B p r z}^{2}+\left(\frac{\partial x_{i j}}{\partial(\Delta T)} \cdot u_{T}\right)^{2}+\left(\frac{\partial x_{i j}}{\partial(\alpha)} \cdot u_{\alpha}\right)^{2}}$

Based on the adopted assumptions, computational formulas were developed, and the values of individual uncertainty components were calculated using the STATISTICA computerized computing system. An assessment of uncertainty of the load test was also conducted. Uncertainty and its components for measuring the positional displacements in the $\mathrm{X}, \mathrm{Y}, \mathrm{Z}$ axes at the maximum displacements during testing are

\begin{tabular}{|c|c|c|c|c|c|c|}
\hline \multirow{4}{*}{ 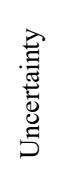 } & \multirow{2}{*}{\multicolumn{2}{|c|}{$\frac{X}{1100 \mathrm{~mm}}$}} & \multirow{2}{*}{\multicolumn{2}{|c|}{$\frac{\mathrm{Y}}{1500 \mathrm{~mm}}$}} & \multirow{2}{*}{\multicolumn{2}{|c|}{$\frac{\mathrm{Z}}{900 \mathrm{~mm}}$}} \\
\hline & & & & & & \\
\hline & $\begin{array}{l}\mathrm{m}=\mathbf{0} \\
{[\mathrm{kg}]}\end{array}$ & $\begin{array}{l}\mathrm{m}=8.6 \\
{[\mathrm{~kg}]}\end{array}$ & $\begin{array}{l}\mathrm{m}=\mathbf{0} \\
{[\mathrm{kg}]}\end{array}$ & $\begin{array}{c}\mathrm{m}=8.6 \\
{[\mathrm{~kg}]}\end{array}$ & $\begin{array}{l}\mathbf{m}=\mathbf{0} \\
{[\mathrm{kg}]}\end{array}$ & $\begin{array}{c}\mathrm{m}=8.6 \\
{[\mathrm{~kg}]}\end{array}$ \\
\hline & \multicolumn{2}{|c|}{$\begin{array}{l}\text { range of uncertainty } \\
\text { values }[\mu \mathrm{m}]\end{array}$} & \multicolumn{2}{|c|}{$\begin{array}{c}\text { range of uncertainty } \\
\text { values }[\mu \mathrm{m}]\end{array}$} & \multicolumn{2}{|c|}{$\begin{array}{c}\text { range of uncertainty } \\
\text { values }[\mu \mathrm{m}]\end{array}$} \\
\hline$u_{A}$ & \pm 7.137 & \pm 2.225 & \pm 10.262 & \pm 4.121 & \pm 0.843 & \pm 16.752 \\
\hline$u_{B \cos }$ & \pm 0.000 & \pm 0.000 & \pm 0.000 & \pm 0.000 & \pm 0.000 & \pm 0.000 \\
\hline$u_{B A b b}$ & \pm 0.000 & \pm 0.000 & \pm 0.000 & \pm 0.000 & \pm 0.000 & \pm 0.000 \\
\hline$u_{B d r m}$ & \pm 0.000 & \pm 0.000 & \pm 0.000 & \pm 0.000 & \pm 0.000 & \pm 0.000 \\
\hline$u_{\text {Bprz }}$ & \pm 0.175 & \pm 0.175 & \pm 0.375 & \pm 0.375 & \pm 0.175 & \pm 0.375 \\
\hline$u_{B T}$ & \pm 0.058 & \pm 0.058 & \pm 0.058 & \pm 0.058 & \pm 0.058 & \pm 0.058 \\
\hline$u_{B \alpha}$ & \pm 0.001 & \pm 0.001 & \pm 0.001 & \pm 0.001 & \pm 0.001 & \pm 0.001 \\
\hline$u_{c}$ & \pm 7.140 & \pm 2.232 & \pm 10.268 & \pm 4.139 & \pm 0.861 & \pm 16.76 \\
\hline$U$ & \pm 14.28 & \pm 4.464 & \pm 20.536 & \pm 8.278 & \pm 1.722 & \pm 33.51 \\
\hline
\end{tabular}
given in Table 1.

Table 1. Uncertainty and its components during laser interferometer measurement of robot arm positioning in axes $\mathrm{X}, \mathrm{Y}, \mathrm{Z}$, with and without static load

Table 1 seems to indicate that the predominant component of the uncertainty budget for laser interferometer measurement is the standard uncertainty $u_{A}$ (the statistical component representing the difference in measurement results). The consequence of the significant value of standard uncertainty is the value of complex standard uncertainty $u_{c}$ and extended uncertainty $U$. Other components of uncertainty resulting from the properties and characteristics of the laser interferometer $\left(u_{B c o s}, u_{B A b b}, u_{B d r m}, u_{B p r z}\right) \quad$ and estimation of the impact of temperature on measurement accuracy $u_{B T}$ and estimation of the coefficient of thermal expansion $u_{B \alpha}$ were shown to only slightly affect the value of complex standard uncertainty and extended uncertainty. From the results presented in Table 1 it can be stated that the application of load to the effector of the tested robot constitutes an important factor influencing the value of uncertainty. It can be stated that loading the effector with a mass of $8.6 \mathrm{~kg}$ gives a stabilizing effect on the examined axes $\mathrm{X}, \mathrm{Y}$, indicating that the conducted research works were of static character. The reverse effect of the uncertainty estimation was obtained, however, for the results from the tests in the direction of the $\mathrm{Z}$ axis (vertical axis). This can be explained by the significant elastic deformations of loaded robot arms.

\section{Conclusion}

Accuracy and repeatability of positioning are key parameters of industrial robots, which determine their usability in support of processes of different manufacturing technologies. However, the determination of these quantities must be related to the measurement uncertainty estimate used in the measurement method. Although modern robots have high reproducibility and relatively high accuracy to meet most applications, it should be borne in mind that these parameters may deteriorate over the machine operation time. This affects 
the dispersion measure and the standard uncertainty of measurement for the measurement method used.

The analysis of uncertainty presented in the paper indicates that the components of the uncertainty budget take relatively low values, which proves that the method chosen for the given research task is correct. It should be noted that interferometer measurements are performed as static measurements, i.e. in certain positions and usually without load on the robot arm by the mass of the displaced elements. In addition, it is only possible to perform measurements at linear displacement in a certain plane. Any change in the measuring plane or travel direction of the robot arm, however, requires the optical system to be repositioned. The authors see some research opportunities using a laser interferometer to evaluate the effect of the weight ratio of the effector and robot arms on the different positions of the work space on the repetition of positioning. This was proved by the results of research and analysis of uncertainties during the static load of effector with mass of $8.6 \mathrm{~kg}$. Of course, the robot arm might be loaded with more mass (max. load of the tested robot $20 \mathrm{~kg}$ ), but from the experience of the authors the result is that the length of the measuring path is corrected by the system. This is due to the change of the trajectory with large overhangs and long paths (lack of parallelism resulting from increased bending moment and elastic deformation of the arms). It can therefore be concluded that the effect of weight of the effector and robot arms is crucial when assessing the uncertainty of the laser interferometer measurement, especially in the vertical axis ( $\mathrm{Z}$ axis). Another problem is the inertia displaced by the mass arm assembly and the maintenance of the preset position (problem with position stabilization and position overshoot) which further limits testing under load.

Despite the limitations, the laser interferometer allows measurements to be performed with extremely low measurement uncertainty, which is very small with respect to the accuracy and repeatability of the positioning of industrial robots.

Although the method employed in this work is dedicated to CNC machine tools, it can also, to a certain extent and with some restrictions, be used to test the accuracy and repeatability of the positioning of industrial robots.

\section{References}

1. P. Majda, D. Rozkrut, Adv. Manuf. Sci. Technol. 39, 3 (2015)
2. P. Majda, M. Pajor, Mechanik, 11 (2016)

3. J. Honczarenko, Roboty przemysłowe. Budowa i zastosowanie (WNT, Warszawa, 2010)

4. J. Józwik, D. Ostrowski, Wybrane problemy badawcze robotów przemysłowych (Wydawca Politechnika Lubelska, 2016)

5. J. Józwik, I. Kuric, L. Semotiuk, Communications, 3A, (2014)

6. J. Józwik, M. Czwarnowski, Adv. Sci. Technol. Res. J., 9, 28 (2015)

7. J. Jozwik, L. Semotiuk, I. Kuric, Adv. Sci. Technol. Res. J. 9, 28 (2015)

8. G.M. Krolczyk, J.B. Krolczyk, R.W. Maruda, S. Legutko, M. Tomaszewski, Measurement $\mathbf{8 8}$ (2016)

9. A. Glowacz, Z. Glowacz, Infrared. Phys. Technol. 81 (2017)

10. M. Slamani, A. Joubair, I. Bonev, Ind. Rob. 42, 6 (2015)

11. M. Slamani, A. Nubiola, I. Bonev, Ind. Rob. 39, 1 (2012)

12. E. Feldshtein, J. Józwik, S. Legutko, Adv. Sci. Technol. Res. J., 10, 30 (2016)

13. G.M. Krolczyk, P. Nieslony, J.B. Krolczyk, I. Samardzic, S. Legutko, S. Hloch, S. Barrans, R.W. Maruda, Measurement, 70 (2015)

14. P. Nieslony, G.M. Krolczyk, K. Zak, R.W. Maruda, S. Legutko, Precis. Eng. 47 (2017).

15. G.M. Krolczyk., R.W. Maruda, P. Nieslony, M. Wieczorowski, Measurement, 94 (2016).

16. K. Young, C.G. Pickin, Ind. Rob. 39, 6 (2000)

17. G. Alici, B. Shirinzadeh, Mech. Mac.h Theory, 40, $8(2005)$

18. A. Angelidis, G.Ch.Vosniakos, Int. J. Precis. Eng. Man. 15, 1 (2014)

19. C. Gong, J. Yuan, J. Ni, Int. J. Mach. Tool Manu. 40, 14 (2012)

20. P.S. Shiakolas, K.L. Conrad, T.C. Yih, Int. J. Model. Simul. 22, 3 (2002)

21. B. Shirinzadeh, Ind. Rob. 25, 1 (1998)

22. J. Swevers, W. Verdonck, J.DeSchutter, IEEE Contr. Syst. Mag. 27, 5 (2007)

23. W. Zhenhua, X. Hui, Ch. Guodong, S. Rongchuan, L. Sun, Ind. Rob. 41, 5 (2014) 